\title{
Diffusive gradient in thin-films (DGT) as risk assessment and management tools in the Central Witwatersrand Goldfield, South Africa
}

\author{
H Mengistu $^{1 *}$, O Roeyset ${ }^{2}$, A Tessema $^{3}$, TA Abiye $^{4}$ and MB Demlie ${ }^{5}$ \\ ${ }^{1}$ Council for Geoscience, Private Bag X112, Pretoria 0001, South Africa \\ ${ }^{2}$ Norwegian Institute for Water Research (NIVA), Gaustadalléen 21, N-0349 Oslo, Norway \\ ${ }^{3}$ Council for Geoscience, Private Bag X112, Pretoria 001, Gauteng, South Africa \\ ${ }^{4}$ School of Geosciences, University of the Witwatersrand, Private Bag X3, PO Box Wits 2050, Johannesburg, South Africa \\ ${ }^{5}$ School of Geological Sciences, University of the Kwazulu-Natal, Private Bag X54001, Durban, South Africa
}

\begin{abstract}
Diffusive gradient in thin-films (DGT) technology was used to monitor bio-available metals and the tool was developed for risk-based pollution assessment and liability apportionment in the Witwatersrand Goldfields, South Africa, where there is widespread mine-related pollution. DGT technology is a passive sampling technique whereby metal species are selectively diffused from polluted water through a diffusion layer and trapped by an inner chelating resin, giving rise to time-weighted average concentrations.

The results show that the concentrations of most hazardous metals recorded from grab samples are higher than values recorded from DGT samplers, resulting in inaccurate input information to risk assessors, the public and decision makers. DGT samplers deployed along upper, middle and lower reaches of Elsburgspruit, a stream southeast of Johannesburg, provided data which could assist in evaluating the source and evolution of metals along the stream length. DGT samplers deployed in 5 augers at different depths around a tailings dam showed that liming and trenching fails to contain deep seepage of trace metals. The results highlight the potential of using DGT samplers as a monitoring tool for providing accurate metal pollution information, assessing source and evolution of metals in streams or rivers for apportionment of liabilities, and evaluating the success of current contaminant containment methods.
\end{abstract}

Keywords: Diffusive gradient in thin-films, binding gel, hydrogel, grab samples, diffusive boundary layer

\section{Background information}

The Witwatersrand gold mining operations have been active for over 100 years, and some of the mines in the region are among the oldest in South Africa (Bernand, 2000). The Central Witwatersrand Goldfield, one of the 6 goldfields in the region, is located south of Johannesburg city, Gauteng Province, South Africa. The site is one of the oldest goldfields in the country and in the world (Fig. 1). After more than a century of mining, with most mines in the basin being in a state of closure because of the dwindling resource, the substantial multi-faced impacts of mining on the ecosystem (soil, landform, groundwater and surface water regime, biota) started to be felt in the 1990s. These impacts include, among others, surface/groundwater pollution, flooding of the mine voids, ground stability problems, and the consequences of high-level release of deleterious pollutants into the ecosystem. It is estimated that, in the Central Witwatersrand Goldfield, $35 \mathrm{M} \ell / \mathrm{d}$ and a maximum of $50 \mathrm{M} \ell / \mathrm{d}$ of mine-water will decant to the surface if the rebounding groundwater table is allowed to rise to surface (Lin, 2010). Moreover, most of the 60 tailings dams and waste rock dumps in the area ooze polluted water discharges into groundwater and surface water further complicating the pollution scenario. Therefore, there is a need to comprehensively evaluate and assess regional geochemistry in order to ascertain the rate and

\footnotetext{
* To whom all correspondence should be addressed.

핀 +27 12 841-1507; fax: +27 86 513-7713;

e-mail: hmengistu@geoscience.org.za

Received 16 February 2011; accepted in revised form 14 December 2011.
}

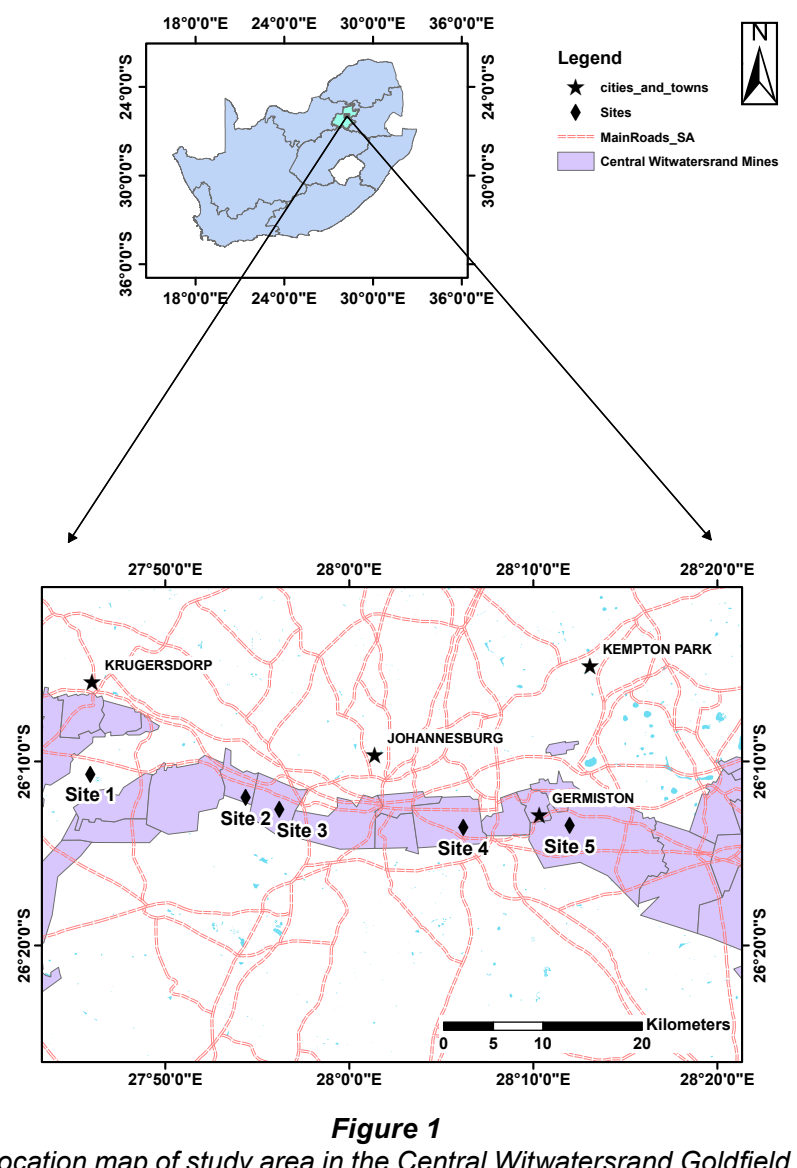

Location map of study area in the Central Witwatersrand Goldfield 
quantity of acid mine drainage generated from the old mines and mine waste dumps, due to the complex nature and long history of mining in the Witwatersrand Goldfields.

Analytical data resulting from samples taken using the conventional grab sampling method, according to South African sampling guidelines, is likely to have high levels of uncertainty for the following reasons: the experience of the sampler, sample storage, and the magnitude of concentration not being timeaveraged but a snapshot value, and not necessarily representing the labile or bio-available fraction of the chemical species (Weaver et al., 2007). In conventionally-acquired samples, measured concentrations of pollutants and specifically metals represent the sum of all uncomplexed free ions, looselycomplexed and strongly-complexed species. Any interpretation and conclusion based on total concentrations and not effective concentrations is likely to be far from accurate and may not represent the real situation. Monitoring of mine drainage has in the past been undertaken by using conventional grab sampling of surface waters and groundwaters from boreholes and surface water bodies.

The current project, funded through a co-operation between the Norwegian Institute for Water Research (NIVA), the National Research Foundation (NRF) and the Council for Geoscience, was initiated to apply diffuse gradient in thin films (DGT) technology in the Witwatersrand mining district as part of the Witwatersrand Central Basin Mine Water Apportionment Pilot Study Programme. To date, the application of passive sampling using DTG samplers has never been utilised in South Africa, where there are currently several operational and abandoned mines throughout the country which have left a complex legacy of environmental pollution.

Several DGT samplers were deployed in streams, reservoirs, evaporation dams, tailings dams and boreholes in the Witwatersrand area, with duplicates and a snap/grab water sampling programme utilised for comparative purposes. Generally, the purpose of DGT technology application was to:

- Assess the suitability of DGT samplers compared to conventional grab samples in risk-based monitoring

- Appraise stream pollution and evolution of metals along the water course qualitatively

- Explore the use of DGTs in measuring the success of pollution-control schemes

\section{Introduction}

DGT is a passive sampling technology, based on a simple procedure of measuring soluble metals, which diffuse through a filter and accumulate on a binding agent, the hydrogel. DGT is designed to selectively bind only the species of interest and to accurately control the transport of the substances to the device, allowing the concentration in solution during deployment to be calculated from the laboratory measurement. DGT has been successfully applied in a variety of environmental monitoring projects related to hazardous radionuclides, trace metals, organic contaminants and pharmaceuticals, to measure chemical release at a controlled rate (Pierzynski et al., 2005). The mobility of selected metals $(\mathrm{Cd}, \mathrm{Zn}$ and $\mathrm{Pb})$ in the rhizosphere was successfully assessed in the Czech Republic with DGT samplers (Fischernova et al., 2005). DGT samplers were also used to assess the bio-availability of aluminium (Al-toxicity) to the fish population in Norway and to successfully determine the cause of massive fish deaths along the Norwegian northsea coast (Lia et al., 2006, Røyset et. al., 2005). Monitoring of highly-fluctuating metal concentrations was successfully done using DGTs and results were evaluated against other methods (Chemcatcher) on the River Meuse, France (Allen et al., 2007) It is also possible to calculate free ion activity by using different diffusive layers (gels) to trap inorganic and organic species separately and then conducting speciation calculations (Kalis, 2006). Since the inception of the use of DGT samplers, several applications of the samplers have helped to solve what has been a tedious and high uncertainty sampling method in Australia and the USA (Larner, and Seen, 2005). The method has been validated with hundreds of research papers and roughly 60 Ph.D. theses, and DGT performance was evaluated for many of the 55 trace metals (Garmo et al., 2003). The application of DGT samplers is currently focusing on standardisation of the method through research institutes (Lancaster University) and the International Network of Acid Prevention (INAP), while research continues on manufacturing of advanced membranes (Zhao et al., 2002) focusing on specific metals of highly complex geochemistry, such as uranium at different solution conditions.

Diffusion of metals occurs through the diffusive boundary layer (DBL) which separates the bulk solution from the binding gel. Measured data accuracy can be improved by using different diffusion coefficients for the different layers (DBL, the hydrogel layer and the Chelex-impregnated hydrogel layer) provided that the total thickness is in excess of $1.5 \mathrm{~mm}$, which is the case in still waters and in highly diluted systems (Gaabass et al., 2009). However, in highly mixed and homogenous conditions, a diffusion coefficient can be used without causing significant errors in the data. The metals, released over a period of time, based on the specific metal's rate of dissociation, are measured by analysing the Chelex layer on which the metal species are captured. In other words, organically- or inorganically-complexed metals have to dissociate during transport through the diffusive layer, be collected on the Chelex membrane and be time-averaged. Measured data will be useful in developing site-specific water quality criteria and waste-load allocation models, and may become a low-cost, highly sensitive complement to toxicity testing for routine monitoring. DGT samplers generally have a detection limit as low as $0.1 \mu \mathrm{g} / \ell$ and can function effectively within extreme solution concentrations typical of contaminated conditions.

Currently, different types of gels are available in the market, including Fe-oxide, mercury iodide, Chelex and ammonium molybdophosphate (AMP), to effectively and selectively bind phosphorus, sulphides, metals and radioactive cesium, respectively (Zhao et al., 2002). New resin gels, Duolite GT73 or Iontosorb AV-MP, were found to be more accurate for measuring bio-available mercury than Chelex gels, in a study conducted in the Czech Republic (Divis et al., 2009). A similar comparison of Chelex gel with mercaptopropyl functionalised resin and Speron-Thiol for accurately measuring mercury in aquatic systems has been conducted (Clarisse and Hintelmann, 2006; Docekalova and Divis, 2004). Special phosphate discs (Whatman P81, DE81, etc.) are manufactured by Whatman International, UK, and are being validated by a few research groups (Lia et al., 2006; Zhao et al., 2002), with specific application for binding uranium at a relatively wider $\mathrm{pH}$ range. It is worth mentioning that the complex uranium geochemistry is a cause for concern in the accuracy of uranium uptake by the standard Chelex gel.

The DTG technique is superior to other sampling methods in that it accumulates chemicals continuously from water and can provide time-weighted average (TWA) concentrations of pollutants over the exposure period, based on Fick's first law of 
diffusion whereby the diffusive mass flux $(J)$ can be calculated (Eq. (1)):

$$
\mathrm{J}=\mathrm{D} \frac{d C}{d X}
$$

where:

$\mathrm{D}$ is the diffusion coefficient $\left(\mathrm{cm}^{2} \cdot \mathrm{S}^{-1}\right)$ and

$\frac{d C}{d X}$ is the concentration gradient $\left(\mathrm{mol} \cdot \mathrm{cm}^{-4}\right)$ $\overline{d X}$

DGT samplers are simple to install and easy to operate with a reasonable cost. Details on installation, deployment, storage, calibration and other procedures can be found in Zhang (2002). DGT samplers measure in-situ labile metal fractions which are bio-available (effective concentration), including flux, by providing accurate data for speciation calculation and for determination of metal dissociation rates.

\section{Materials and methods}

DGT deployment sites were selected on the basis of location relative to pollution sources and representativeness of the type of water source (stream, borehole, mine return-water dam, wetland and lake) for the purpose of risk assessment. The first site, having 3 separate locations, was chosen to represent the 3 major mine compartments of the Central Witwatersrand Goldfield (western, central and eastern) whereby 1 site is within the western compartment, 3 sites are in the central compartment and 1 site is in the eastern compartment. The second site of DGT deployment, intended to assess pollution source, is located on a highly-polluted stream passing through a number of mine-waste dump sites. The third deployment site, intended to assess the possibility of using DGTs to monitor existing pollution control schemes, is situated at the foot of a local tailings dam site.

DGT sampler kits and iminodiacetate chelating resin (Chelex-100) and Whatman P-81 membranes were purchased from the DGT research group at Lancaster University, UK. A DGT sampler is a simple kit with a $25 \mathrm{~mm}$ diameter plastic backing cylinder and a front cap with a window of $20 \mathrm{~mm}$ diameter (Fig. 2a). A layer of resin gel is placed on the base, facing upward and acting as a diffusion layer of hydrogel overlying a chelating resin below a filter membrane, which is used to facilitate diffusion of metals over a period of time (Fig. 2b). Collectively, the hydrogel and the filter membrane are known as the diffusion layer. DGT samplers were collected within a period of 3 to 31 days after deployment at the chosen sites. The samplers were put into water-tight sealed bags which then were placed in cooler boxes (portable ice chests) at a temperature of $4^{\circ} \mathrm{C}$. Upon arrival at the laboratory, the samplers were disassembled using a screwdriver to take out the inner membrane and dispose of the hydrogel, filter and plastic cap. The inner membrane was acid bathed in $1 \mathrm{~m} \ell$ of concentrated nitric acid, which has an elution capacity of $95 \%$ according to Royset (Royset et al., 2005), for $12 \mathrm{~h}$, to elute metals.

The samples were then diluted to $10 \%$ for another 10 to $12 \mathrm{~h}$ to prepare them for ICPMS analyses. Analyses were performed using a Perkin Elmer ELAN@ DRC II ICP-MS system that was calibrated according to the manufacturer's specifications. A standard quantitative analysis method was used and the calibration standards were prepared from Merck VI multi-element standard solution. Indium and Iridium were added as internal standards to samples and calibration solutions to correct for instrument drift and factors influencing physical sample introduction. Samplers in an ultra pure water were

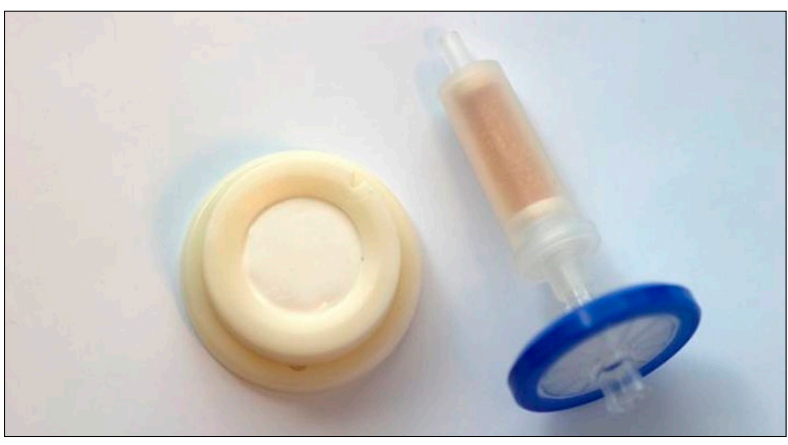

Figure 2a

DGT samplers for free water and pore-water metal assessment

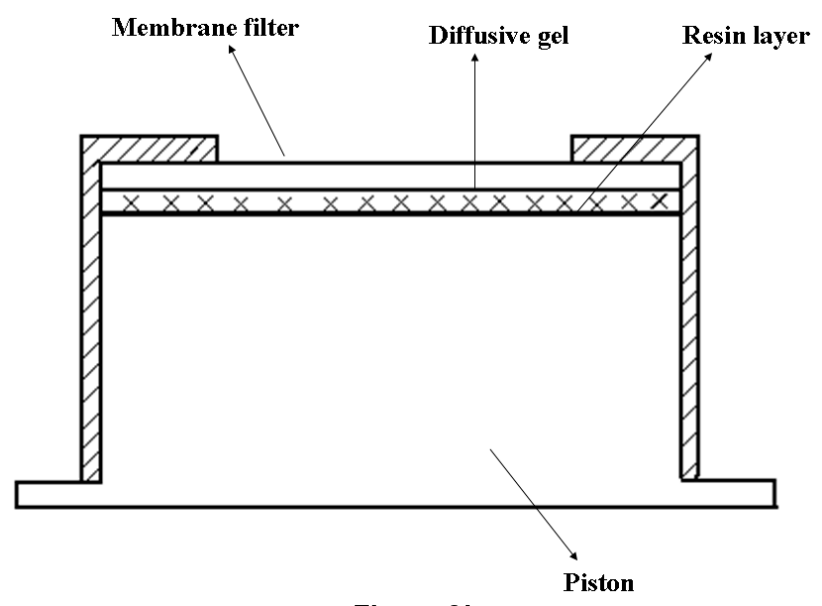

Figure 2b

Schematic section of DGT samplers showing the top cap, filter membrane, diffusive gel and resin layer used for chelating metals

used as a blank and water samples using the conventional grab sampling method were taken at selected sites for comparison purposes. All samples considered were unfiltered samples and were not acidified, since the turbidity of all samples was very low. Reproducibility was maintained through double deployment and by making use of blanks. Containers used to digest DGT samplers were acid-leached for $24 \mathrm{~h}$, rinsed with ultrapure water and dried before use to prevent contamination. After acid leaching, and controlled dilution, the leftover resin material was filtered to avoid scavenging of metals from the bulk solution.

Diffusion coefficients of specific metals of interest, determined at room temperature $\left(25^{\circ} \mathrm{C}\right)$, were adapted from earlier works by various research groups such as Norwegian Research for Water Studies and DGT Research Centre at Lancaster University, UK (Zhang and Davidson, 1995), and were corrected using average temperature of the water during and after deployment. Temperature correction of viscosity was calculated using the equation (Eq. (2)) (Miller, 1924):

$$
\log \frac{\eta_{0}}{\eta_{t}}=1.37023 \frac{(t-25)+0.000386(t-25)^{2}}{109+t}
$$

where:

$\eta_{0}$ is viscosity at $25^{\circ} \mathrm{C}$

$\eta_{t}$ is the viscosity at a measured temperature

Similar to viscosity, diffusion is highly temperature-dependent and temperature effect on diffusion is calculated using the Stokes-Einstein formula (Miller, 1924): 


$$
\frac{D_{t} \eta_{t}}{T_{t}}=\frac{D_{0} \eta_{0}}{T_{0}}
$$

where:

$D_{t}$ (length ${ }^{2} /$ time) is the diffusion constant (coefficient) at a measured temperature $t$,

$\eta_{t}$ is the viscosity of the solution at a measured temperature $t$, whereas

$D_{0}$, and $\eta_{0}$ denote the diffusion constant and viscosity at $T_{0}$ which is the room temperature $\left(25^{\circ} \mathrm{C}\right)$.

Diffusion coefficients of individual species across the diffusive layer were not determined and are known to not be significantly affected by the concentration of other metal species in solution, making individual calibration unnecessary (Røyset et al., 2005; Docekalova and Divis, 2004). Temperature-corrected diffusion coefficients of metal species, thickness of the filter membrane and the diffusive layer $(0.1 \mathrm{~cm})$ as well as DGT exposure area $\left(3.14 \mathrm{~cm}^{2}\right)$ were used to calculate the uptake rate using formula:

$$
\text { Uptake rate (volume/time) }=\frac{D_{t} A}{L}
$$

where:

$D_{t}$ (length ${ }^{2} /$ time $)$ is the diffusion constant at a measured temperature $t$,

$A$ is the DGT exposure area $\left(\right.$ Length $\left.^{2}\right)$ and

$L$ (Length) represents the total thickness of filter and dif-

fusive layer through which diffusion of the metals occurs.

Individual calculation of diffusion coefficient is not necessary because of an assumed complete mixing of the solution and the negligible total thickness of the filter membrane and diffusive layer (roughly $1 \mathrm{~mm}$ ) compared to the thickness of the bulk solution. Therefore, 1 temperature-corrected diffusion coefficient is used for every metal. It has been described that in cases of high DBL in still water, inaccuracy due to use of a single diffusion coefficient may incur between 4 and $8 \%$ error, but this still appears to be small (Røyset et al., 2005).

The time-integrated uptake volume is then calculated by multiplying the uptake rate and the total deployment time in units of volume. Using the laboratory-measured metal concentrations and considering the dilution volume, the mass of the diffused metal is calculated. Finally, the effective, time-averaged metal concentration is calculated by dividing the mass of the diffused metal with the total flux (uptake volume).

Data validation was done using duplicate deployment, field blanks and spot sampling of the water body where DGT samplers were placed. Analyses of field blanks after a 72-h leaching of the empty high density polyethyelene (HDPE) bottles show high levels of $\mathrm{Al}$, due to possible contamination, for which corrections were made by subtracting the concentration of the acid leachate analytes from the concentrations obtained from the DGT samplers. The major cations $(\mathrm{Na}, \mathrm{Be}, \mathrm{Ca}, \mathrm{Mg})$ were not considered due to high uncertainty caused by high concentrations in the blanks. Excessively high concentration of alkali and alkali earth metals could likely limit the sorption capacity of the DGT surface area and therefore incur uncertainty in determining the concentration values of the metals (Royset et al., 2005). Moreover, previous research has shown that concentrations of alkali and alkali earth metals from DGT samplers fitted with a Chelex layer are not accurate and could not be validated (Royset et al., 2005). Water in-situ pH measurement showed that $\mathrm{pH}$ values ranged from 3 to 8 and were within the range ( $\mathrm{pH} 3$ to 10 ) tested to give the best DGT performance (Garmo et al., 2006). Average water temperatures, taken from measurements during deployment and collection, ranged between 16 and $24^{\circ} \mathrm{C}$, and were used to calculate corrected metal diffusion coefficients. Gel sorption capacity is expected to be far from saturation based on previous investigations stating that, even at a rate of $1 \mathrm{mg} / \ell$, it takes up to 300 days of flux to saturate the Chelex resin (Zhang and Davidson, 1995).

\section{Results and discussion}

\section{Duration of deployment}

Deployment time is one of the factors which causes uncertainties in the application of DGT for measuring labile metal concentrations. Previous work on assessing the effect of deployment time shows that the longer the deployment time, in excess of $72 \mathrm{~h}$, the lower the detection limit. According to Garmo et al. (2003), for an exposure period of 1 to 4 weeks, the detection limit is lowered by a factor of 1 to 2 per day.

On the site which represents the 3 subdivisions of the Central Witwatersrand Mine, 2 sets of DGT samplers of Chelex gel were deployed for a period of 3 days (short-term) and 31 days, (long-term) in a borehole, a wetland, a stream and a lake site, to assess the effect of deployment time on the final concentrations. The results presented in Fig. 3 generally show that the long-term deployment results in 1 or 2 orders of magnitude of reduction in concentration from that of short-term deployment, for all chemical species. A previous research study portrayed more or less similar uptake rates for up to $48 \mathrm{~h}$, beyond which the long-term deployments show a slightly decreased uptake for a few species (Garmo et al., 2003). Use of long deployment times accumulates more metal and lowers the detection limit. For instance, for 1-day deployment, the detection limit for a typical DGT device ( $0.8 \mathrm{~mm}$ thick diffusion gel), allowing for substantial dilution (to $1 \mathrm{~m} \ell$ ) on elution, will be $0.01 \mu \mathrm{g} / \ell$ for a detection limit of the final instrumental measurement of 0.1 $\mu \mathrm{g} / \ell$. By optimising procedures, DGT detection limits can be several orders of magnitude lower than $0.1 \mu \mathrm{g} / \ell$. Moreover, the maximum concentration that can be measured depends on the capacity of the resin (Zhang and Davidson, 1995). For 1-day deployment with a typical DGT device, the sorption load is roughly $0.5 \mathrm{mmol} / \ell$, which equates to 30 to $100 \mathrm{mg} / \ell$, depending on the metal type. Therefore, relative reduction of detection limit, during longer deployment allowing accumulation of more metals on the Chelex, must be taken into consideration to explain relatively low concentrations recorded in longterm deployment, as shown in previous similar investigations (Zhang and Davidson, 1995). The $\mathrm{pH}$ of the water was roughly 3 to 8 , which is within the range in which most previous experiments were done. Based on these data and previous suggestions, a deployment time of not more than $72 \mathrm{~h}$ was found to be optimal, consistent with a previous deployment optimisation result (Thomas, 2009).

\section{Comparison of data from DGT versus grab sampling}

DGT samplers were deployed and grab samples were taken at sites representing a borehole, a wetland, a stream and a lake, south of Johannesburg, for laboratory analysis. It should be taken into consideration that the DGT data considered for comparison represents only short-term (72 h) deployment. The resulting concentration versus metal plot shows that the concentrations of most trace metals recorded from conventional grab samples are higher by up to 1 order of magnitude than the corresponding concentration data from the DGT samplers 


\section{Figures 3a through 3d Long-term (31 days) and short- term (3 days) TWA concentrations $(\mu \mathrm{g} / \mathrm{l})$ of DGT samplers deployed in Angelo Stream, Elsburg Wetland, Victoria Lake and New Canada Borehole}

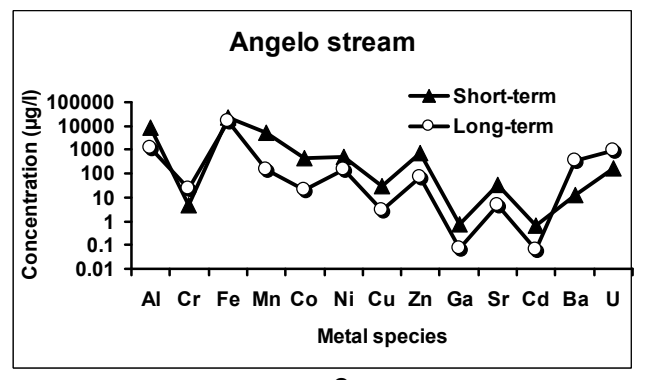

$3 a$

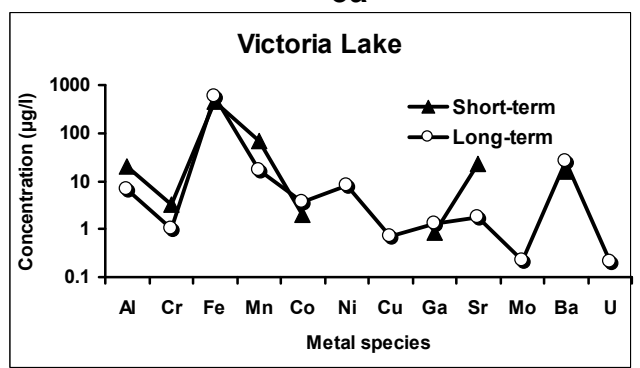

3c

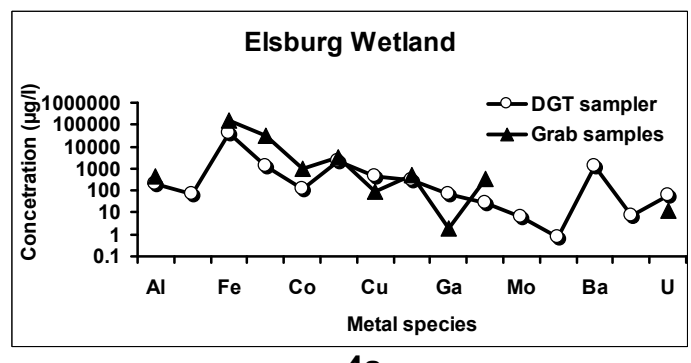

4a

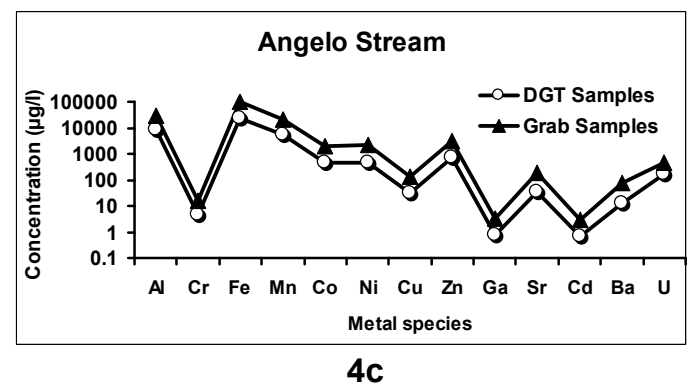

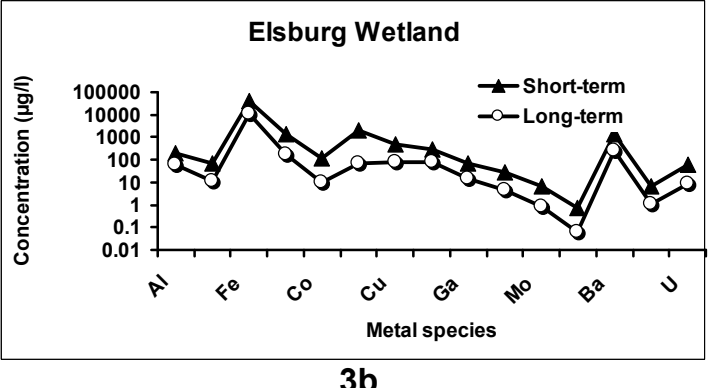

3b

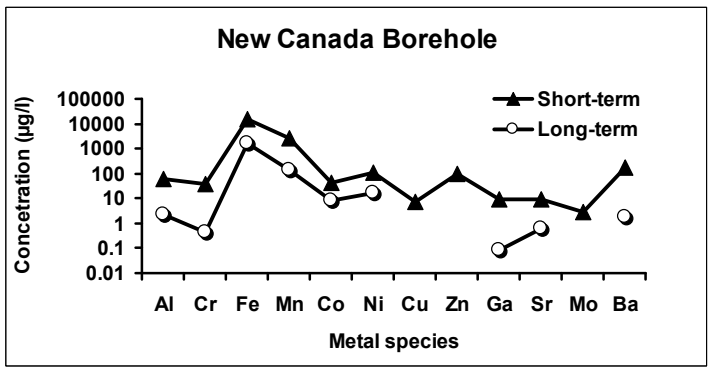

3d

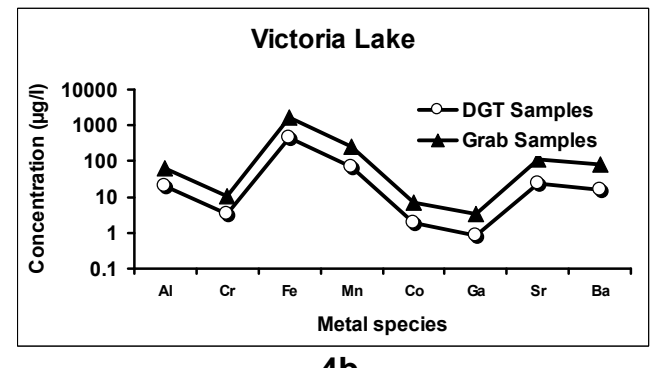

4b

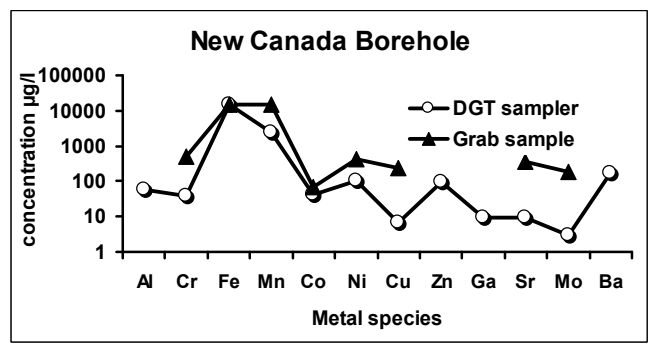

4d
(Figs. 4a to $4 d$ ). The result supports the theory that humic/ organic-bound metals, colloid-metal complexes and metals sorbed on other suspended particles could have been excluded from being diffused and captured by the DGT samplers. The result is also consistent with the observation that organo-metal complexes form rather strong associations, making the toxic metals not bio-available (Allen et al., 2007). Grab samples, on the other hand, represent total metal concentration including un-dissociated metal complexes. The discrepancy in concentration (less in DGTs than in grab samples) is consistent for most metals, but greater or roughly equal concentrations of Co and $\mathrm{Zn}$ are observed in the Elsburg Wetland, as was the case for $\mathrm{Fe}$ and $\mathrm{Co}$ in the New Canada Borehole sample (Figs. 4a through 4d). Individual explanations for discrepancies between the DGT and grab sample metal concentrations are deemed speculative; however a clear and uniform concentration difference between the DGT and grab samples for the majority of trace metals was observed in still waters (Elsburg Wetland and New Canada Borehole), as opposed to the fast-moving
Angelo Stream and slow-moving Victoria Lake waters. The less-pronounced concentration difference in fast-moving water bodies is more reliable and accurate than data from still water bodies because the effect of discrepancy in diffusion coefficients between the different layers (diffusive boundary layer, hydrogel layer and the inner Chelex-impregnated gel layer) is more significant in still waters than fast-moving streams. In still waters the diffusive boundary layer is so significant that a separate diffusion coefficient is required for improved data quality, especially in pristine waters.

The basic generalisation from the comparison data is that DGT sample concentrations are, in most cases, lower than the respective concentrations from grab sampling, reasonably suggesting that the concentrations from DGT samplers represent the labile fraction of either free metal ions or weaklycomplexed metal radicals, which are bio-available. When concentrations between grab sampling and DGT samplers are close to one another, it implies the absence of strong inorganic or organic complexing ligands, whereby most metal species are 


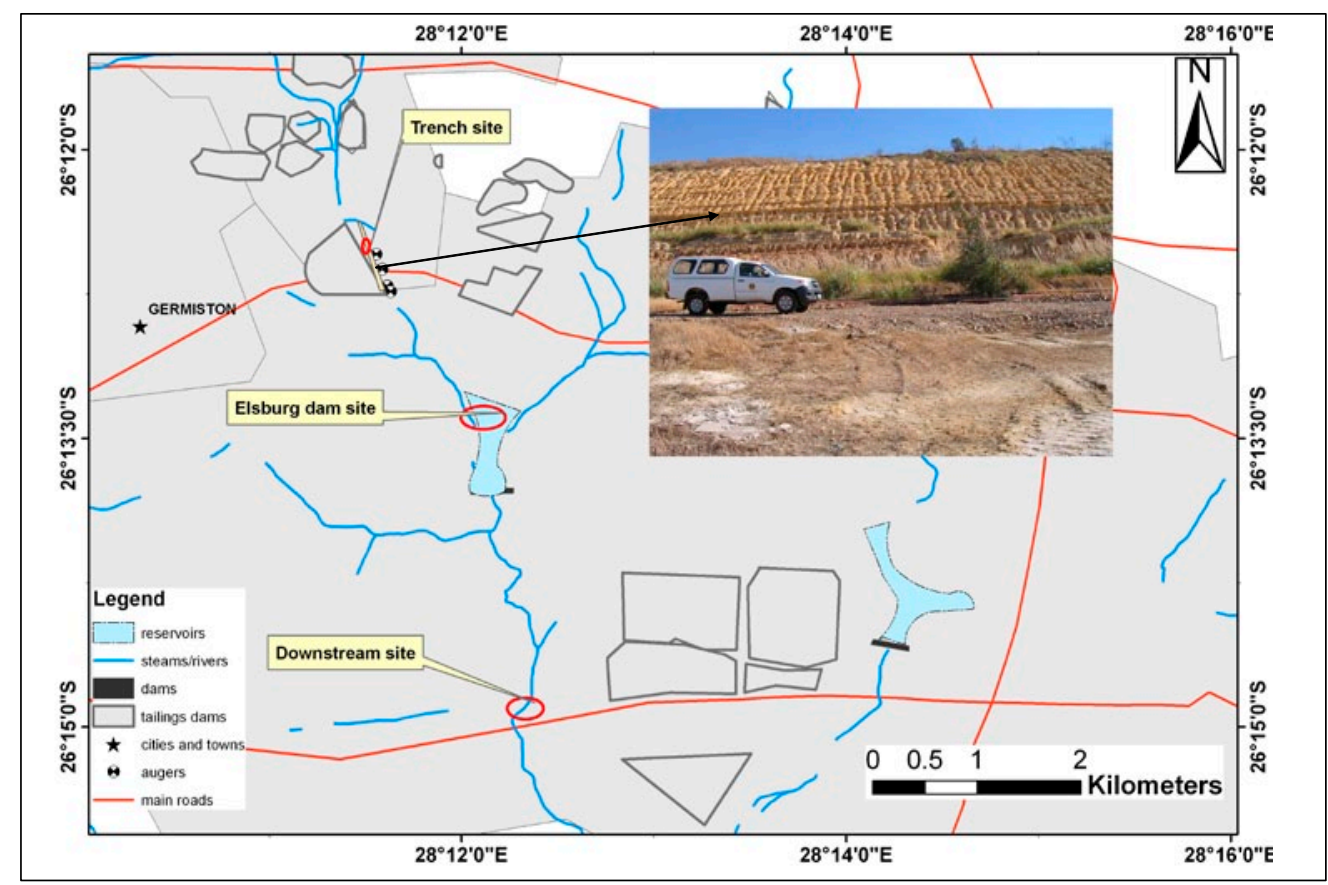

Figure 5

Location map of the Elsburgspruit DGT deployment sites either in the form of free ions or weakly complexed radicals, readily available for biological uptake or diffusion and capture by DGT samplers.

\section{DGT samplers in assessing stream pollution}

On the second site, a number of duplicate DGT samplers were deployed along the upper, middle and lower reaches of the Elsburgspuit in the vicinity of Germiston town, southeast of Johannesburg (Fig. 5). The purpose of the deployment was to assess the evolution of metal pollution along the stream route, as an initial trial of using passive samplers to determine apportionment of pollution liabilities. Three sites were chosen upstream (of Elsburg Dam), at the Elsburg Dam (wetland) and downstream of the Elsburg Dam, as the stream passes from an area of a relatively few sources of contamination through areas hosting a number of tailings dams, waste rock dumps, landfills and other pollution sources

Most metal concentrations, except $\mathrm{U}, \mathrm{Cu}$ and $\mathrm{Al}$, are higher downstream (of Elsburg Dam) than in the middle dam or upstream (of Elsburg Dam) sites, possibly suggesting that there is a continuous input of additional metals along the stream route (Figs. 6a through 6d). The fact that peak concentrations of $U$, $\mathrm{Cu}$ and $\mathrm{Al}$ were detected at the upstream trench site most likely implies that either the downstream mine wastes are relatively poor in $\mathrm{Al}, \mathrm{Cu}$ and $\mathrm{U}$ or that the wetland created by the dam is a sink to the 3 metals. The $\mathrm{pH}$ values measured at the upstream (of Elsburg Dam) site and at the Elsburg Dam site were between 3.5 and 4, possibly favouring the occurrence of most metal species in an uncomplexed form or weakly complexed to inorganic ligand radicals. On the other hand, the roughly neutral $\mathrm{pH}$ is likely to account for increased adsorption of the trace metals under consideration by clay, hydrous ferric oxide (HFO) or organic matter. However, there needs to be thorough additional investigation of the stream sediments, organic matter and other sinks to discover a reliable and certain explanation.

High downstream metal concentrations most probably suggest that the organic material in the artificial wetland created by Elsburg Dam is not enough to trap most of the trace metals,
Elsburg stream site

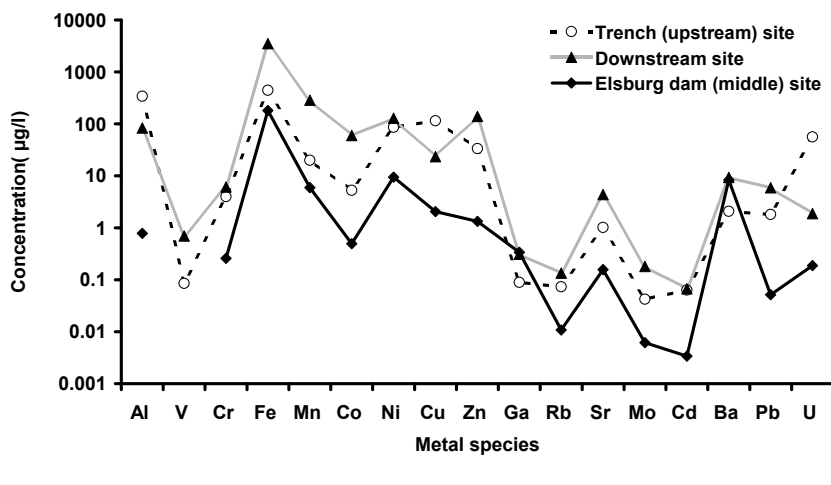

Figure 6

DGT analytical TWA concentrations $(\mu \mathrm{g} / \ell)$ along the Elsburgspruit

perhaps due to additional input or exceedance of the sorption capacity of the sorbents. Nevertheless, with proper selection of sampling sites and dense sampling points, there is a potential to apply DGT sampling for stream water quality assessment, conveniently, in future liability apportionment projects.

\section{DGT samplers for tailings dam site monitoring}

The third site is located in the Central Witwatersrand Goldfield where several tailings dams are currently exposed to wind and flood erosion threatening soil and water resources. Detailed observation of the site indicates that the mine waste dump is a highly exposed and degraded tailings dam with highly-eroded steep side slopes, located a few hundred meters from a large township east of Germiston town (Fig. 5). A wetland, presumably generated by the seepage from the tailings dam, is situated immediately east of the tailings dam. Several local mines in the area put pollution control trenches (toe drains) around tailings dams or widely use liming to prevent and manage mine drainages from polluting surface water bodies and to buffer the $\mathrm{pH}$ of the discharge water, respectively. Five shallow auger holes of 


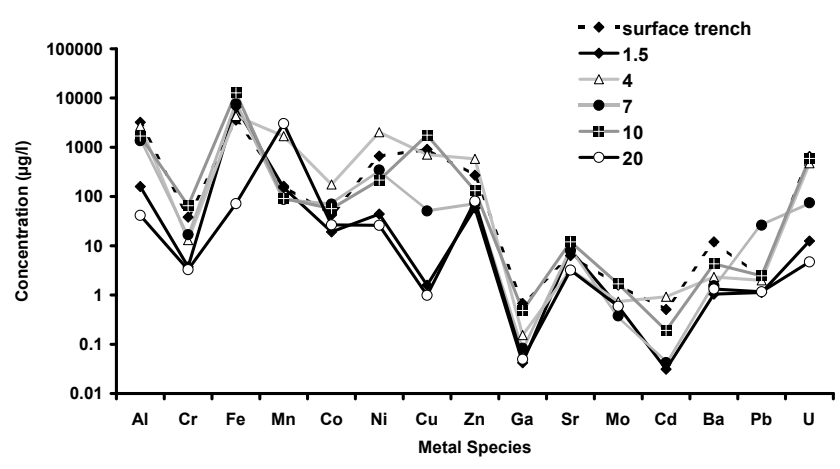

Figure 7

DGT TWA concentrations $(\mu \mathrm{g} / \mathrm{l})$ at different depths at Delmore village trench site

various depths, of $1.5 \mathrm{~m}, 4 \mathrm{~m}, 7 \mathrm{~m}, 10 \mathrm{~m}$ and $20 \mathrm{~m}$, strategically positioned downstream of the tailings dam in a north-south direction, were drilled, and DGT samplers were placed at the bottom to assess pore water quality. Depth to water level ranges from surface at the southernmost auger hole ( $1.5 \mathrm{~m}$ deep) to 18 $\mathrm{m}$ below surface at the northernmost auger hole $(20 \mathrm{~m})$.

The data for the toe drain show that about $30 \%$ of the metals have relatively higher concentrations here than in the pore water at deeper levels. On the other hand, a little over $50 \%$ of metal concentrations from pore water at $20 \mathrm{~m}$ depth below surface were relatively lower than those from pore water at less than $20 \mathrm{~m}$ depth (Fig. 7). The concentration profile of metals suggests that the magnitude of concentration of a specific metal at a certain depth is not only a function of metal speciation but also of metal sorption and metal-metal interaction. Therefore, it is not trivial to extract a metal concentration versus depth trend from the graphs. Accurate explanation for concentration gradients for individual trace metals may not be feasible at this point as there is no clear trend between concentrations and depth.

The local seepage wetland seems to act as a sink for various trace metals from this and other upstream tailings dams, but subsequent analyses of water downstream of the site at the entrance of the dam clearly indicate that the wetland is simply not effective in reducing the metal concentration. Deployed DGTs at the immediate outlet of the wetland were repeatedly stolen and it was not possible to confirm the extent to which the metals are captured at the wetland.

A 3D visualisation of a few metals was done using Environ-

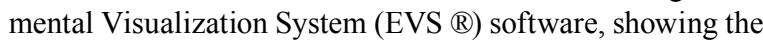
spatial distribution of the auger holes, depth and corresponding concentrations. The results depict high concentrations of $\mathrm{Mn}$ at deep zones $(20 \mathrm{~m})$, almost in contrast to other trace metals including Fe (Figs. 8a through 8d). In several previous cases, $\mathrm{Mn}$ and Fe have been demonstrated to behave very similarly in subsoils (Mansfeldt, 2004; Smedley and Edmunds, 2001). The most northern portions of the visualisation do not represent real field conditions because of a limited data grid and were not considered in any interpretations (Figs. 8a through 8d). Similar tailings analyses elsewhere in the Witwatersrand basin found an increase in concentration of $\mathrm{Mn}$ along with $\mathrm{SO}_{4}$ and $\mathrm{Zn}$ down the profile (Govender et al., 2009). Detailed explanation of the metal gradient in the soil profile will require detailed physical and chemical characterisation of the tailings and the soil, and geochemical modelling to be conducted, which was beyond the scope of this investigation. Nonetheless, it is possible to generalise that the analytical result for selected metals, depicted in 3D visualisation, shows high levels of trace metals in the deeper soil profiles, which underscores the fact that liming and trenching are not effective in containing vertical contaminant movements. More importantly, the result in general emphasises the potential of using passive samplers (DGT) to monitor the effectiveness of existing pollution control methods.

\section{Conclusions}

Passive samplers are superior to the conventional grab sampling method in accurately measuring the concentration of labile metals which are bio-available, averaged over a certain period of time. Errors associated with sample storage and experience

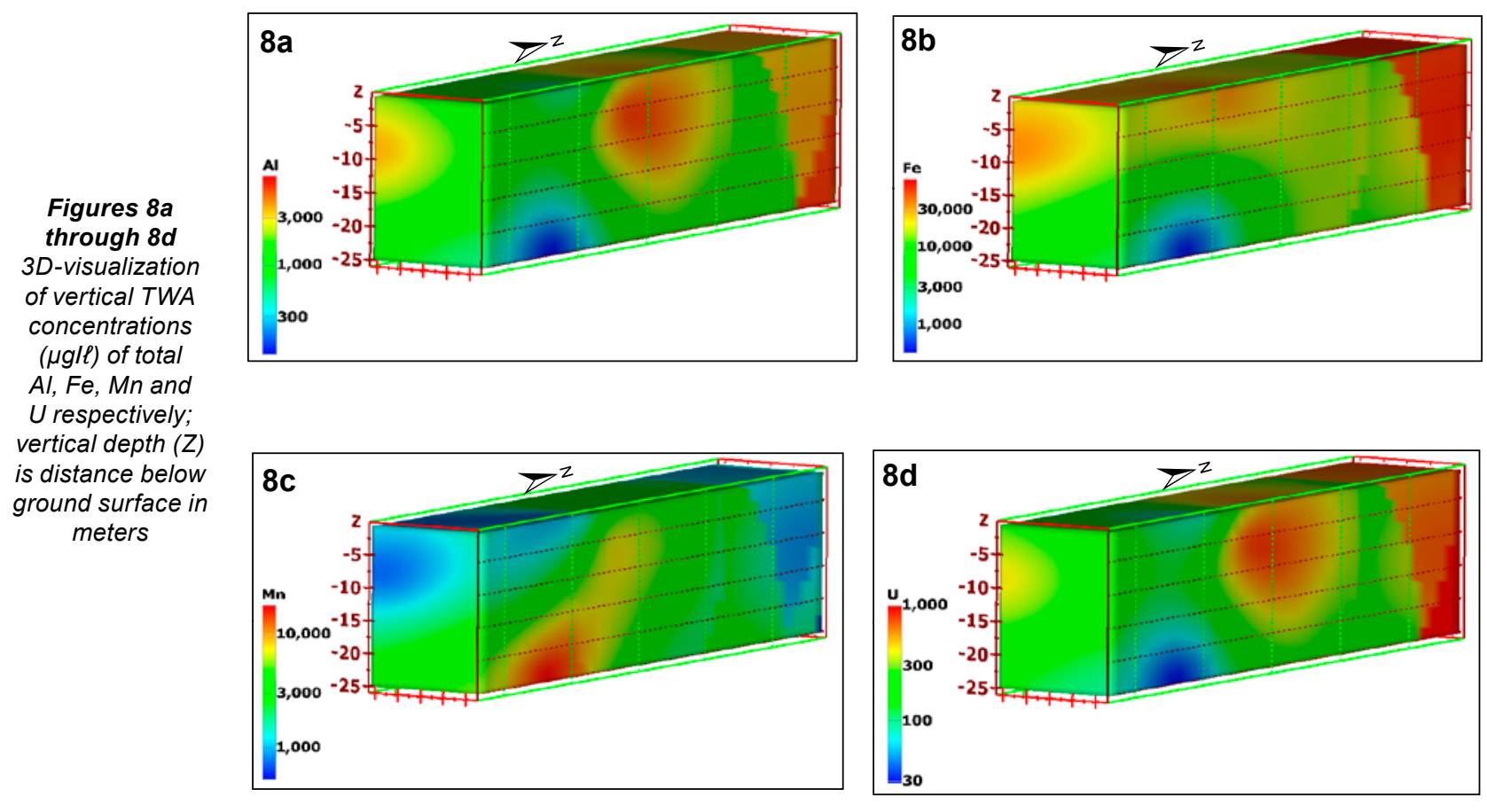


of the sampler can be reduced to an acceptable level with passive samplers. Inherent errors in using a uniform diffusion coefficient for all layers (the diffusion layer, the hydrogel and Chelex-impregnated layer), not doing DBL correction, and from the effect of competing ligands and metals, are within acceptable limits $(<8 \%)$ and are greatly out-weighed by several advantages of using DGTs.

DGT samplers show considerable potential for monitoring mine-related water pollution at lower costs. In the Central Witwatersrand Goldfield, DGT samplers allowed the determination of bio-available metals more accurately than by conventional grab sampling. Total concentrations determined from grab samples do not necessarily represent the amount of metal available to organisms. More importantly, metal standards for surface/ground waters and soils compiled on the basis of measured total concentrations are considered conservative values. There is no negative implication of using such values in compliance monitoring as the standards set are not for real exposure limits. Moreover, it is possible to calculate free ion activity by using different diffusive layers to trap inorganic and organic species separately.

DGT samplers show great potential to monitor the evolution of metal species along polluted streams and perhaps provide information enabling pollution source apportionment in areas where contamination emanates from several point sources and allocation of liabilities is very difficult if not impossible. Moreover, the concentration data can assist in the design of effective stream pollution management schemes.

Monitoring of acid mine generation control schemes can be improved by using DGT samplers. DGT samplers can be deployed at chosen depths and locations with ease and relatively low installation cost, to examine the risk of pollution to surface water and groundwater resources which are vital supplies of water to the community and to assess the effectiveness of current containment methods.

\section{Acknowledgements}

We would like to thank the Council for Geoscience and the National Research Foundation (NRF) of South Africa for providing unlimited access to office and field equipment and funding. Special thanks to Daniel Sebake of CGS for his relentless help in producing maps, Thokozani Ntuli of CGS for assisting in field data collection, Hilde Cronwright of CGS for laboratory analyses and Karl Aanes of the Norwegian Institute for Water Research (NIVA) for rendering consultation during the field data collection.

\section{References}

ALLEN IJ, KNUTSSON J, GUIGUES N, MILLS GA, FOUILLAC A and GREENWOOD R (2007) Evaluation of the Chemcatcher and DGT passive samplers for monitoring metals with highly fluctuating water concentrations. J. Environ. Monit. 9 672-681.

BARNARD HC (2000) An Explanation for the 1:500,000 hydrogeological map of Johannesburg 2526. Department of Water Affairs and Forestry, Pretoria.

CLARISSE O and HINTELMANN H (2006) Measurements of dissolved methylmercury in natural waters using diffusive gradient in thin films (DGT). J. Environ. Monit. 89 1242-1247.

DIVIS P, SZKANDERA R, BRULIK L, DOCEKALOVA D, MATUS $P$ and BUJDOS M (2009) Application of new resin gels for measuring mercury in diffusive gradients in thin films technique. Anal. Sci. 25 575-578.

DOCEKALOVA H and DIVIS P (2004) Application of diffusive gradient in thin films technique (DGT) to measurement of mercury in aquatic systems. Talanta 65 1174-1178.

FISCHERNOVA Z, SZAKOVA J and PAVLIKOVA T (2005) The application of diffusive gradient in thin films (DGT) for assessment of changes in $\mathrm{Cd}, \mathrm{Zn}$ and $\mathrm{Pb}$ mobility in rhizosphere. Plant Soil Environ. 51 (12) 532-538.

GAABASS I, MURIMBOH DJ and HASSAN MN (2009) A study of diffusive gradients in thin films for the chemical speciation of $\mathrm{Zn}(\mathrm{II}), \mathrm{Cd}(\mathrm{II}), \mathrm{Pb}(\mathrm{II})$, and $\mathrm{Cu}(\mathrm{II})$ : The role of kinetics. Water Air Soil Pollut. 202 131-140.

GARMO OA, NAQVI KR, RØYSET O and STEINNES E (2006) Estimation of diffusive boundary layer thickness in studies involving diffusive gradients in thin films (DGT). Anal. Bioanal. Chem. 386 (7-8) 2233-2237.

GARMO OA, RØYSET O, STEINNES E and FLATEN TP (2003) Performance study of diffusive gradients in thin films for 55 elements. Anal. Chem. 75 (14) 3573-3580.

GOVENDER A, BEZUIDENHOUT A, VAN ZYL A and ROUSSEAU $P$ (2009) Prediction of seepage emanating from a tailing storage facility (TSF) in an arid climate. Proc. Int. Mine Water Conf., 19-23 October 2009, Pretoria. Water Institute of Southern Africa \& International Mine Water Association. 873-881.

LARNER BL and SEEN AJ (2005) Evaluation of paper-based diffusive gradients in thin film samplers for trace metal sampling. Anal. Chim. Acta 539 (1-2) 349-355.

LIA W, ZHAO J, CHUNSHENG L, KISERA S and CORNETTA R (2006) Speciation measurements of uranium in alkaline waters using diffusive gradients in thin films technique. Anal. Chim. Acta 575 (2) 274-280

LIN L (2010) Personal communication. Geohydrology task leader of Central Witwatersrand Mine Water Management Company, Council for Geoscience, Pretoria, South Africa. 10 November 2010.

MANSFELDT T (2004) Redox potential of bulksoil and soil solution concentration of nitrate, manganese, iron and sulfate in two gleysols. J. Plant Nutr. Soil Sci. 167 7-16.

MILLER CC (1924) The Stokes-Einstein Law for diffusion in solution. Proc. R. Soc. London A 106 724-749.

PIERZYNSKI M, MICHAEL J and SCHNEEGURT M (2005) Evaluation of chemical and biological assays as indicators of toxic metal bioavailability in soils. US EPA Final Report, EPA Grant Number: R829418E02. URL: http://cfpub.epa.gov/ncer abstracts/ index.cfm/fuseaction/display.abstractDetail/abstract/6108/report/F.

RØYSET O, ROSSELAND BO, KRISTENSEN T, KROGLUND F, GARMO ØÅ and STEINNES E (2005) Diffusive gradient in thin films sampler predicts stress in Brown Trout (Salmo trutta L.) exposed to aluminum in acid fresh waters. Environ. Sci. Technol. 39 1167-1174.

SMEDLEY P and EDMUNDS W (2001) Redox pattern and trace element behavior in the East Midlands Triassic Sandstone aquifer, UK. Groundwater 40 44-58.

THOMAS P (2009) Metals pollution tracing in the sewerage network using the diffusive gradients in thin films technique. Water Sci. Technol. 60 (1) 65-70.

WEAVER MC, CAVE L and TALMA AS (2007) A comprehensive guide for groundwater sampling methods. WRC Report No. TT 303/07. Water Research Commission, Pretoria, South Africa.

ZHANG H and DAVISON W (1995) Performance characteristics of diffusion gradients in thin films for the in situ measurement of trace metals in aqueous solution. Anal. Chem. 67 3391-4000.

ZHAO W, TEASDALE P, JOHN R and ZHANG S (2002) Application of cellulose ion exchange membrane as a binding phase in the diffusive gradient in thin films technique for measurement of trace metals. Anal. Chim. Acta 464 330-339. 